\title{
Antioxidant Phytocomplex with Antitumor Activity
}

\author{
Olga G. POZDNYAKOVA ${ }^{1}$, Galina A. BELAVINA ${ }^{1 *}$, Alexander N. AVSTRIEVSKIKH ${ }^{2}$, \\ Andrey A. VEKOVTSEV ${ }^{2}$, and Valery M. POZNYAKOVSKY ${ }^{1}$ \\ ${ }^{1}$ Kuzbass State Agricultural Academy, Kemerovo, Russian Federation \\ 2 "Art Life" Research and Manufacturing Association, Tomsk, Russian Federation \\ *Correspondence: lina.belavina29@yandex.ru
}

\begin{abstract}
A phytocomplex in the form of a biologically active additive (BAA) with targeted antitumor activity due to the synergistic effect of the components of the antioxidant formulation has been developed. It includes peach leaf, extract; vitamins $E$ and $C$ and $\beta$-carotene. Sanitary-hygienic and sanitary-toxicological safety studies were carried out during 39 months of storage at $25^{\circ} \mathrm{C}$ in a dry, dark place. The hygienic wellbeing of the product is shown. The shelf life is set to not more than 3 years from the date of manufacture. Physicochemical, organoleptic and nutritional values are defined as regulated indicators. The functional orientation of the product is due to the content of ascorbic acid, tocopherol and $\beta$-carotene, respectively, at the level of 30, 10 and $2 \mathrm{mg}$ in 1 capsule. A new technology for the encapsulated form of dietary supplements has been proposed. It has several advantages compared to its analogues such as the availability of hardware design, the efficiency of water extraction, the absence of oxidative and hydrolytic reactions due to the hard shell of the capsule, sparing process parameters that ensure the preservation of biologically active ingredients and their active principles. $A$ feature of the developed dietary supplement is the bioavailability of the components of the formulation and their milder effect on the body without the manifestation of side effects.
\end{abstract}

Keywords: phytocomplex, formulation, technology, antitumor activity, regulated quality and safety indicators.

\section{Introduction}

The development of specialized products, including dietary supplements using natural plant materials, is one of the priority areas of modern nutrition. It plays an important role in the prevention and comprehensive treatment of common diseases, one of which is immunodeficiency $[1,2]$. The problem of immunodeficiency and related oncological diseases require effective preventive measures and comprehensive treatment [3]. The determining vector in solving this trend is the use of natural biocomplexes with directed functional properties $[4,5]$.

\section{Literature Review}

It is known that active forms of oxygen, nitrogen oxides, hydroperoxides and other free radicals are constantly formed in the human body. They are used by the immune system (at normal physiological amounts) to destroy bacteria, viruses, damaged and dying cells, 
toxic metabolites and other negative factors of internal and the external environment. Under conditions of accumulation of an excessive amount of free radicals, they acquire the function of molecule killer, which in order to restore their charge interact with the molecules of cell walls and other structures, carrying out a negative process of oxidation and destruction. Free radicals can penetrate into the bloodstream, causing a chain reaction of organs and systems damage and as a result the onset and development of diabetes mellitus, atherosclerosis, cerebral stroke, myocardial infarction and other common diseases. Genetic mutations are especially dangerous. DNA molecules are damaged and the transmission of genetic information is disrupted under the influence of free radicals. It is a risk factor for cancer pathologies. Evidence concerning the negative effects of free radicals on collagen and elastin is available. As a result, the elasticity of the walls of blood vessels, muscles, cartilage and tendons is lost. The synovial fluid is not formed in the proper amount and the process of destruction of the intervertebral discs and joints starts.

\section{Materials and Methods}

Plant materials and vitamin preparations with synergistic properties in inhibiting the oncological process were used as materials. Standard and special methods were used to study the quality and safety of laboratory and industrial samples of developed products [6]. Samples were taken using a random sample. We visually examined the appearance and color. The smell and taste were examined organoleptically. We determined capsule weight (average), vitamin $C$ according to Global Fund XI issue 2, the content of vitamin $E$ - FR.1.31.2005.01810, Guidelines 08-47 / 184; $\beta$-carotene - GOST 8756.22-80. Microbiological indicators were determined in accordance with GOST 10444.12, GOST 10444.15, GOST 26668, GOST 26669, GOST 26670, GOST 30726, GOST R 52814, GOST R 52816; toxic elements - GOST 30178, GOST 26930, GOST 26927, GOST 26929, GOST R 51766, GOST R 51637; the content of pesticides according to GOST 30349.

\section{Results}

A new antioxidant formula of dietary supplements has been developed. It is based on peach leaf extract with the addition of synergistic components such as vitamins $C, E$ and provitamin $\beta$-carotene. Their biochemical and pharmacological characteristics that determine the functional properties of a specialized product are given [7].

Peach leaf extract (Prunus persica). It is rich in plant substances of the phenolic structure, in particular flavonoids, which have an antitumor, choleretic, capillary-strengthening, antioxidant and immunomodulating effect. Peach leaf extract is traditionally recommended for digestive diseases. This is due to its antispasmodic, anti-inflammatory and choleretic effect. The properties of the extract are aimed at ensuring the detoxification function of the liver tissue, the normalization of the function of bile, the gastrointestinal tract, including the bile ducts. The extract has a positive effect on metabolic processes in the pancreas. It is used for various diseases of liver, pancreatitis, cholecystitis, etc. A positive prophylactic effect is noted for gastritis, peptic ulcer and gastric cancer. The relief of the gastric mucosa and the ability of parietal cells to produce hydrochloric acid are restored under the action of the extract. Dyspeptic disorders disappear and appetite improves. The extract has antitumor activity. It helps to reduce cancer toxicity, as well as mitigate the manifestations of side effects caused by antitumor 
drugs. Thus, a dietary supplement containing an extract obtained from peach leaves has a versatile nature of action, which gives grounds for its use as an immunostimulant and a mean of improving protective mechanisms and non-specific resistance of the human body and the quality of life and prevention of various diseases.

Vitamin $E$ (tocopherol acetate). It is an important food component for the body. The immunological orientation of the vitamin is realized through its antioxidant properties. It prevents the damaging effect of free radicals, inhibits the oxidation of unsaturated lipids, which affects the metabolic processes in lipoprotein cell membranes and organelles and ensures their structural integrity. It protects other fat-soluble vitamins from destruction by oxygen, promoting the absorption of vitamin $A$ and $D$. Tocopherol performs a structural function by interacting with phospholipids of biological membranes. It has the properties of activating the utilization of protein substances by the body. It blocks the activity of protein breakdown enzymes, thus contributing to their metabolism, supports metabolic processes in the muscles and promotes the accumulation of glycogen in them. Vitamin $\mathrm{E}$ has a positive effect on the function of the genital and other endocrine glands protecting hormones from oxidation. Chronic tocopherol deficiency leads to irreversible transformations of testicles (male germ cells) and epithelial glands. Tocopherol reduces the risk of blood clots, increases the resistance of red blood cells to hemolysis and strengthens blood vessels. It is a prophylactic of atherosclerosis and thrombophlebitis. Vitamin E performs the function of an antioxidant. It is recommended to prevent cancer pathologies in case of adverse effects of radiation and chemical factors on the body. Vitamin E promotes the production of red blood cells, delays the aging process, helps to prevent cancer, diabetes and cardiovascular diseases and increases physical stamina, improving oxygen utilization.

Ascorbic acid (vitamin C). It has a directed antibacterial effect, which helps to increase resistance to various infections and strengthen the body's immune system. Like tocopherol, it exhibits antioxidant properties and inhibits free radicals, thereby reducing the risk of cancer. Vitamin C prevents the formation of free radicals, reduces the risk of developing tumors and delays the aging process. It positively affects the metabolism of iron and vitamin B6, improves vascular elasticity. Vitamin $C$ has a regulatory effect on redox reactions, activates the body's metabolism.

Beta carotene. The biochemical functions of beta-carotene are associated with its participation in the following transformations: it is provitamin $A$ and it implements specific antioxidant functions. The antioxidant properties of provitamin are associated with the protection of cell membranes from the negative effects of free radicals. Metabolizing in retinol it regulates bone growth, participates in the formation of intercellular substance, collagen and elastic fibers of the connective tissue, smooth muscle of blood vessels, regulates the restoration and full functioning of the skin and mucous membranes of the digestive, respiratory and urogenital tracts of retinoic acid, which is a hormonal form of vitamin A.

In the form of retinyl phosphate, vitamin A is involved in the transfer of mannose and fructose during the biosynthesis of cell membrane glycoproteins. This mechanism explains the importance of beta-carotene as a precursor to retinol for the immune system. The individual properties of beta-carotene are associated with the possibility of prevention and complex treatment of cancer and cardiovascular pathologies. 
The presented characteristic served as the basis for the scientific substantiation of the qualitative and prescription composition of dietary supplements. Peach leaf extract is included as the main ingredient along with other biologically active substances that have a synergistic effect on the declared properties, mg in 1 capsule: dry peach extract - 102 (flavonoids in terms of rutin, not less than 2); vitamin C - 30; tocopherol acetate, $50 \%$ (tocopherol - 10); beta-carotene, 20\% (beta-carotene - 2).

Anti-caking agents Kafos - 25; talc - 15 and calcium stearate - 5.1; carrier silicon dioxide 5 are used as the secondary means. The total weight of the gelatin capsule is $600 \mathrm{mg}$.

The studies of organoleptic, physico-chemical and microbiological indicators of safety quality in accordance with the requirements of the regulatory document were carried out. The product was stored for 39 months in a dry, dark place at a temperature of no higher than $25^{\circ} \mathrm{C}$. The results are presented in Tables 1,2 .

Table 1. Sanitary hygiene safety indicators

\begin{tabular}{|c|c|c|c|}
\hline \multicolumn{2}{|c|}{ Indicators } & Regulated content & Actual level \\
\hline \multicolumn{2}{|c|}{$\begin{array}{l}\text { The number of mesophilic aerobic and } \\
\text { facultative anaerobic microorganisms, } \\
\text { CFU / g, not more than }\end{array}$} & $5 \times 10^{4}$ & $4 \times 101$ \\
\hline \multicolumn{2}{|c|}{ Yeast and mold, CFU / g, not more than } & 100 & Less than 10 \\
\hline \multirow{3}{*}{$\begin{array}{l}\text { The mass of the } \\
\text { product }(\mathrm{g}) \text { in } \\
\text { which it is not } \\
\text { allowed: }\end{array}$} & E. Coli & 1.0 & Not found \\
\hline & $\begin{array}{l}\text { Pathogenic, } \\
\text { including salmonella }\end{array}$ & 10.0 & Not found \\
\hline & Coliforms & 0.1 & Not found \\
\hline
\end{tabular}

Table 2. Sanitary toxicological safety indicators

\begin{tabular}{l|l|c|c}
\hline \multicolumn{2}{c}{ Indicators } & $\begin{array}{c}\text { Regulated content, mg / kg, } \\
\text { not more than }\end{array}$ & Actual level \\
\hline \multirow{4}{*}{$\begin{array}{l}\text { Toxic } \\
\text { elements }\end{array}$} & Lead & 5.0 & Less than 0.83 \\
\cline { 2 - 4 } & Cadmium & 1.0 & 0.055 \\
\cline { 2 - 4 } & Mercury & 1.0 & Less than 0.05 \\
\cline { 2 - 4 } & Arsenic & 3.0 & Less than 0.02 \\
\hline \multirow{3}{*}{ Pesticides } & Hexachloran (isomers) & 0.1 & Less than 0.005 \\
\cline { 2 - 4 } & $\begin{array}{l}\text { Dichlorodiphenyltrichloroeth } \\
\text { ane and its metabolites }\end{array}$ & 0.1 & Not found \\
\cline { 2 - 4 } & Heptachlor & Not allowed $(<0.002)$ & Not found \\
\cline { 2 - 4 } & Aldrin & Not allowed $(<0.002)$ & \\
\hline
\end{tabular}


The data presented indicate the sanitary well-being of the specialized product at the end of 39 months of storage. This allowed us to determine the implementation period such as 3 years under the mentioned conditions and 3 months at the necessary margin of safety.

Regulated organoleptic characteristics and indicators of nutritional value, positioning the functional properties of the developed product are determined (Table 3).

Table 3. Regulated quality indicators of dietary supplements

\begin{tabular}{l|c}
\hline \multicolumn{1}{c}{ Indicators } & Characteristics \\
\hline Form & Gelatin Capsules (Detachable) \\
\hline Color & From brown to light brown \\
\hline Smell and taste & Specific \\
\hline Capsule weight (average), mg & $540-660(600)$ \\
\hline \multicolumn{2}{|c}{ Vitamins, mg in one capsule } \\
\hline Vitamin C & $24-36(30)$ \\
\hline Tocopherol & $7-13(10)$ \\
\hline Beta carotene & $1.6-2.4(2)$ \\
\hline
\end{tabular}

A production technology with the definition of adjus table parameters has been developed. It includes the following stages (Figure 1).

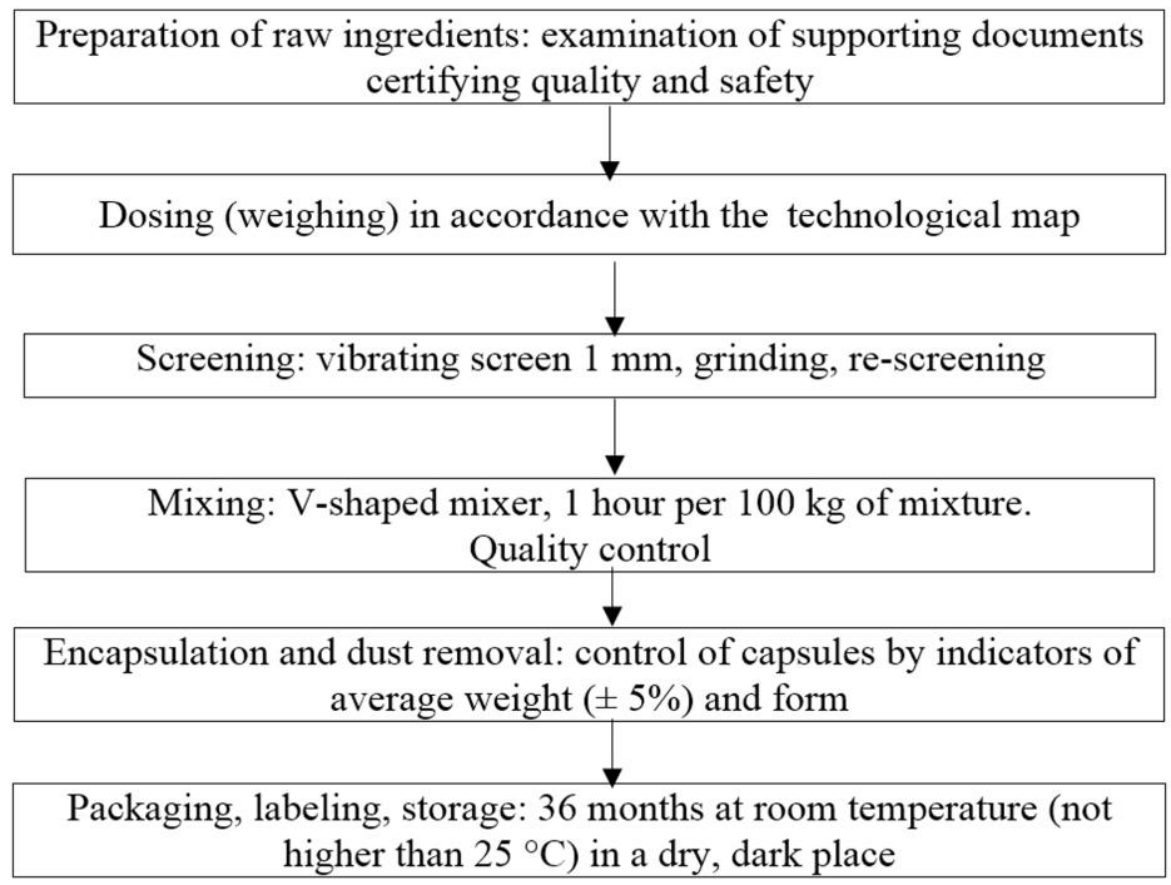

Figure 1. Technological scheme for the production of encapsulated forms of dietary supplements 
Preparation of raw materials. The raw materials used must have the permission of the state bodies of the Russian Federal Service for Supervision of Consumer Rights Protection and Human Well-Being if there are documents confirming the quality and safety.

Dosage of prescription components. It occurs in the following order: dry extract of peach leaf, tocopherol acetate, beta-carotene, ascorbic acid, lactose, talc, kafos, aerosil. A hitch of each component is fixed in the technological map. A check is carried out regarding the conformity of the series of raw materials, their quantity and name to the contents of the technological map.

Screening. It is carried out using a vibrating screen with $1 \mathrm{~mm}$ holes. The resulting screenings are placed in a hammer mill, crushed and re-sieved. Lumps and foreign inclusions should be absent when pressing with a pestle on the surface of the mixture.

Mixing. The obtained components are loaded into a V-shaped mixer and mixed at the rate of $100 \mathrm{~kg}-1$ hour. The mixture is sent to a testing laboratory for analysis and a protocol of compliance with the stated requirements.

Encapsulation and dust removal. In the process of encapsulation:

- every 30 minutes the weight (average) of the capsules is monitored. For this purpose 20 capsules and the weight of individual capsules are weighed (20 capsules are weighed alternately). Error shouldn't exceed $\pm 5 \%$ of the specified value;

- every hour the form are assessed;

- dust removal of finished capsules.

Ready-made hard gelatin capsules that meet the requirements of technological documentation in form are weighed, placed in a container with the name, batch number, quantity, production date, operator position and transferred to the packaging stage.

The work tested a method of obtaining a dry extract from peach leaves, including:

Obtaining liquid extraction. Preliminary, the raw materials are submitted for analysis and then are sent to work after receiving the test report. Raw materials are placed in maceration tanks in a uniform layer of $40-50 \mathrm{~kg}$ each. In order to prevent the emergence of raw materials, gratings are installed and heating of the thermal jacket is turned on. Demineralized water preheated to a temperature of $95{ }^{\circ} \mathrm{C}$ is used as an extractant. The first bay is used in a ratio of extractant raw materials of 1:13 taking into account the absorption coefficient of the extracted raw materials, at the second bay - 1:10. The extraction time is 4 hours for each extraction. The volume of extractant is controlled using a special vane counter of hot water 15 "Agidel". The resulting extract is pumped into distribution tanks and also taken into account using a counter. The control the time of extraction and the conformity of the name, quantity, series of raw materials to the technological map are carried out.

Condensation of liquid extract. This process is carried out in a vacuum evaporation unit (VEU). The extract is continuously and gradually fed into the VEU using a vacuum. At the same time the level of evaporation of the liquid should be no more than $10 \mathrm{~cm}$ from the upper edge of the boiling pipes for more uniform operation of the VEU and less spraying. The readings of the vacuum gauges and the temperature of evaporation are recorded. The extract, concentrated to a solids content of at least $25 \%$, is drained, filtered through a sieve into clean containers, weighed, labeled and fed to the drying area within a period 
not exceeding 24 hours, observing the storage temperature of the thick extract $-5{ }^{\circ} \mathrm{C}$. The readings of the vacuum gauges, the evaporation temperature and the level of evaporation of the liquid are monitored.

Obtaining a dry extract by spray drying. The drying and preheating temperature of the spray dryer is $90-95^{\circ} \mathrm{C}$.

The dry extract is unloaded in double plastic bags at the end of drying and blowing the dryer and sealed.

Losses at the stage of spray drying should not exceed $7 \%$ of the total mass of dry extract of the batch obtained.

A feature of the production of dry plant extracts is an individual selection of technology for each type of raw material, temperature, duration of extraction, amount of infusions, concentration for evaporation and drying technological parameters.

Technical documentation has been developed. Authorizing documents for the extract produced have been obtained. Proven technology has several advantages:

- lack of complex hardware design of the process;

- good solubility of biologically active substances of plants and their easy extraction using aqueous extraction;

- the availability of existing principles of the metabolic processes of the body;

- they have a milder effect on the body compared with individual medicines, they are better tolerated, have a low level of side effect and can be used for a long time.

It should be noted that the production process of a specialized product is carried out with gentle technological parameters that exclude the effects of high temperatures and other undesirable effects. This factor, as well as the presence of hard gelatin capsules, which provide a low content of oxygen and moisture, prevents the development of oxidative and hydrolytic processes that lead to negative changes in consumer properties, contributing to the stability of biologically active components of the formulation.

Clinical evidence of the effectiveness and functional orientation of a specialized product has been obtained. The product was included in the diet of patients with acute respiratory diseases. Diet therapy was carried out for 28 days (one capsule twice a day). We studied the clinical symptoms of the disease, the subpopulation of lymphocytes, hematological tests, the amount of IFN- $\gamma$ in the blood. The results showed the presence of an immunomodulatory effect, which was expressed in enhancing the function of immunocompetent cells in relation to the antiviral response. The anti-inflammatory effect was expressed in a decrease in the inflammatory process. Relief of general intoxication syndrome was noted. The positive effect of dietary supplements on the correction of metabolic processes provides a reduction in the duration of the disease and an improvement in the general condition of patients. No side effects were detected.

\section{Discussions}

The obtained data and available literature data allow us to determine the possible mechanism of the effect of the antioxidant phytocomplex on the immunomodulating and antitumor activity of the body (Figure 2). 
The main therapeutic effects of dietary supplements have been determined, which are consistent with available materials from similar studies [8-10]:

- activation of their own antioxidant potential due to additional body protection from an excess of free radicals;

- adaptogenic stimulating effect on individual parts of the immune system with the manifestation of antitumor activity and support of the body during radiation and chemotherapy;

- protection against destruction of lipid-containing cellular structures, prevention of tissue hypoxia in diabetes mellitus, atherosclerosis, anemia, heart failure and other pathologies accompanied by the accumulation of aggressive molecules;

- a positive effect on metabolic processes in connective tissues (protection and restoration of vessels of tendons, cartilage, joints, skin, mucous membranes, etc.);

- choleretic, anti-inflammatory and antispasmodic action, providing an improvement in the detoxification function of the liver, the composition of bile, protection and restoration of the gastric mucosa and, in general, the functioning of the digestive system;

- reducing the risk of cancer, preventing aging processes.

\section{Conclusions}

The materials obtained made it possible to develop recommendations for the use of dietary supplements: for adults, for 1 month during meals, 2 times a day, 1 capsule. The specified amount intake of dietary supplement guarantees the receipt, mg (\% of the recommended daily requirement): vitamin C - 60 (67); Vitamin E - 20 (67); beta-carotene 4 (80).

The competitive advantages of the phytocomplex are the quick, convenient and simple inclusion of polyphenolic compounds in the diet (substances that interfere with the attachment of tumor cells to the walls of blood vessels and inhibit inflammation). The ingredient composition of dietary supplements has a pronounced antioxidant effect and helps to slow down the occurrence of age-related changes in the body.

Activities to test dietary supplements at the production sites of research and production association "Art Life" have been taken. The stability of the specified characteristics is guaranteed by the implementation of ISO 9001, 22000 and GMP rules at the enterprise. 


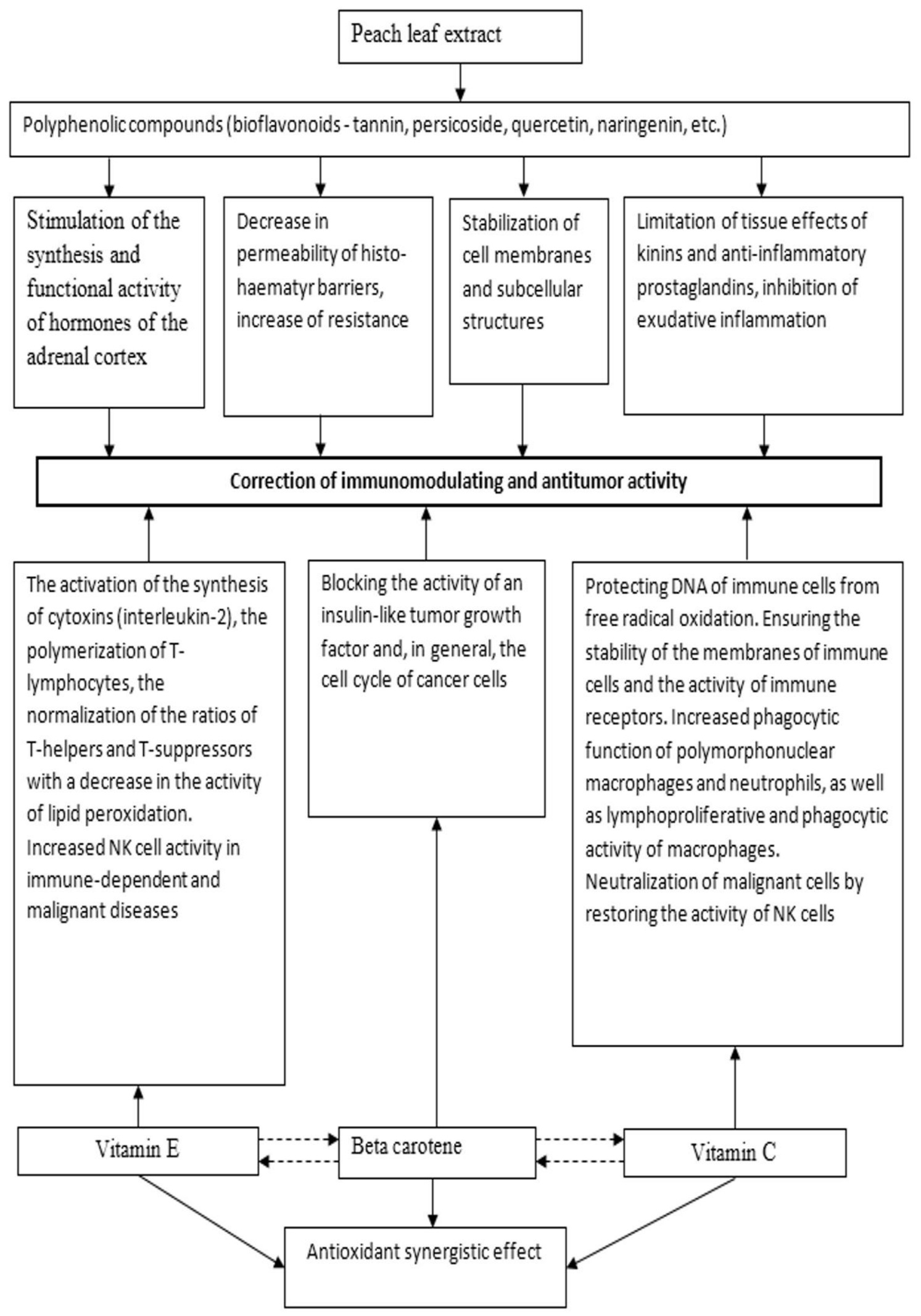

Figure 2. The mechanism of action of dietary supplements on the immunomodulating and antitumor activity of the body 


\section{References}

(1) Gerasimenko, N.; Poznyakovsky, V.; Chelnakova, N. Methodological Aspects of High-Grade Safe Nutrition: Value in Maintaining Health and Working Capacity (in Russian). Human. Sport. Medicine 2017, 17 (1), 79-86. https://doi.org/10.14529/hsm170108.

(2) Poznyakovsky, V. M. The Evolution of Nutrition and the Formation of the Nutrioma of Modern Man (in Russian). Food Industry 2017, 3, 5-12.

(3) Tutelian, V. A.; Sukhanov, B. P.; Spirichev, V. B.; Kudasheva, V. A. Micronutrients in the Nutrition of a Healthy and Sick Person: Vitamin and Mineral Reference Guide (in Rissian); Kolos: Moscow. https://www.books.ru/books/mikronutrienty-v-pitaniizdorovogo-i-bolnogo-cheloveka-106370/ (accessed Feb 20, 2020).

(4) Austrievskikh, A. N.; Vekovtsev, A. A.; Poznyakovsky, V. M. Health food products: new technologies, quality assurance, application efficiency (in Russian); Siberian University Publishing House: Novosibirisk, 2005.

(5) Poznyakovsky, V. M.; Chugunova, O. V.; Tamova, M. Yu. Food Ingredients and Dietary Supplements (in Rissian); INFRA-M: Moscow, 2017.

(6) Eurasian Customs Union. Technical Regulation of the Customs Union 027/2012 "On Safety of Particular Types of Special Foodstuff Including Dietic Clinical and Dietic Protective Nutrition" (TR TS 027/2012) Adopted by Decision of the Council of the Eurasian Economic Commission No. 34 of 15 June 2012. 2012. https://ec.europa.eu/food/sites/food/files/safety/docs/ia_eu-ru_sps-req_decision34_annex_en.pdf (accessed Feb 20, 2020).

(7) Spirichev, V. B.; Shatnyuk, L. N.; Poznyakovsky, V. M. Food Fortification with Vitamins and Minerals. Science and Technology (in Russian); Siberian University Publishing House: Novosibirisk, 2005.

(8) Duy Bao, H. N.; Ohshima, T. Strategies to Minimize Oxidative Deterioration in Aquatic Food Products. In Lipid Oxidation; Elsevier, 2013; pp 345-380. https://doi.org/10.1016/B978-0-9830791-6-3.50014-X.

(9) Deng, G.-F.; Xu, X.-R.; Li, S.; Li, F.; Wu, S.; Li, H.-B. Natural Antioxidants in Food. In Phytochemicals: occurrence in nature, health effects and antioxidant properties; Nova Science Publishers, Inc.: Hauppauge, NY, 2013; pp 147-174.

(10) Surai, P.; Fisinin, V. Natural Antioxidants and Stresses in Poultry Production: From Vitamins to Vitagenes. In The Proceedings of XXV World's Poultry Congress 2016 Invited Lecture Papers; World's Poultry Science Association: Beijing, China, 2016; pp 116-121.

\section{Information about Authors}

Olga Georgievna POZDNYAKOVA: Ph.D. in Engineering, Associate Professor, Doctoral Candidate at the basic department "Food Industry and Functional Nutrition", Kuzbass State Agricultural Academy; 12 Karl Marx Str., Kemerovo, 650021, Russia; e-mail: 79502628552@ya.ru. 
Galina Andreevna BELAVINA: Postgraduate of the basic department "Food Industry and Functional Nutrition", Kuzbass State Agricultural Academy; 12 Karl Marx Str., Kemerovo, 650021, Russia; e-mail: lina.belavina29@yandex.ru.

Alexander Nikolaevich AVSTRIEVSKIKH: D.Sc. in Engineering, Professor, General Director of the Research and Production Association "Art Life"; 8/2 Nakhimov Str., Tomsk, 634034, Russia; e-mail: alexcander@artlife.ru.

Andrey Alekseevich VEKOVTSEV: Ph.D. in Medicine, Deputy General Director for Science and Production of the Research and Production Association "Art Life"; 8/2 Nakhimov Str., Tomsk, 634034, Russia; e-mail: pvm1947@bk.ru.

Valery Mikhailovich POZNYAKOVSKY: D.Sc. in Biology, Professor, Honored Scientist of the Russian Federation, Head of the Scientific and Educational Center "Processing of Agricultural Raw Materials and Food Technology", Head of basic department "Food Industry and Functional Nutrition", Kuzbass State Agricultural Academy; 12 Karl Marx Str., Kemerovo, 650021, Russia; e-mail:pvm1947@bk.ru. 